\title{
MonotomidGen - A matrix-based interactive key to the New World genera of Monotomidae (Coleoptera, Cucujoidea)
}

\author{
Thomas C. McElrath', Olivia F. Boyd², Joseph V. McHugh' \\ I Department of Entomology, University of Georgia, 455 Biological Sciences Athens, GA 30602, USA \\ 2 Department of Integrative Biology, Oregon State University, 3029 Cordley Hall Corvallis, OR 97331, USA \\ Corresponding author: Thomas C. McElrath (monotomidae@gmail.com)
}

Academic editor: M. Thomas | Received 12 July 2016 | Accepted 2 November 2016 | Published 21 November 2016

http://zoobank.org/246CA5EE-8201-40A3-9180-E457D48D4B2E

Citation: McElrath TC, Boyd OF, McHugh JV (2016) MonotomidGen - A matrix-based interactive key to the New World genera of Monotomidae (Coleoptera, Cucujoidea). ZooKeys 634: 47-55. doi: 10.3897/zookeys.634.9857

\begin{abstract}
A matrix-based Lucid ${ }^{\mathrm{TM}}$ key is presented for the twelve genera of Monotomidae (Coleoptera: Cucujoidea) represented in the New World. A general overview is given for the features and technical specifications of an original interactive key for the identification of these genera. The list of terminal taxa included with the key provides a current summary of monotomid generic diversity for the Nearctic and Neotropical regions.
\end{abstract}

\section{Keywords}

interactive key, data matrix, identification, morphology, LUCID, minute clubbed beetles

\section{Introduction}

Matrix-based (also known as interactive, multi-access, multi-entry, or filter-style) keys offer vast advantages over traditional dichotomous identification keys. Some advantages include: freedom to follow more than a single path, ability to use only subsets of characters, integration of non-traditional (e.g., biology, distribution) and overlapping characters, effective use of multi-state characters, and inclusion of numerous graphics (Penev et al. 2009, 2012). These keys have been used successfully 
to overcome the challenges of identification of many groups of organisms, including various flies (Lyons and Dikow 2010; Ceretti et al. 2012), thrips (Mound et al. 2012), aphids (Favret and Miller 2012), and beetles (Lawrence et al. 2010; Lord et al. 2011; Nearns et al. 2016). However, many other challenging groups could use such powerful identification tools.

With 117 described species in twelve genera, the New World Monotomidae (also known as the "minute clubbed beetles") are a small group of mostly mycophagous and predaceous beetles within the superfamily Cucujoidea. The worldwide generic diversity was last reviewed by Sen Gupta (1988). Since that review, nine new genera have been described, including one from the New World (Pakaluk and Ślipiński 1993; Pal 1996; Sen Gupta and Pal 1995). The North American genera were briefly reviewed and an identification key was provided by Bousquet (2002a). Many Nearctic genera have been reviewed relatively recently (Bousquet 1990, 2002b, 2003a, b, c; Bousquet and Laplante 1999). Despite these reviews, identification remains difficult, especially to non-specialists who are unfamiliar with the diagnostic characters. Since Monotomidae are important components of forest ecosystems as predators of scolytine bark beetles (Gregoire et al. 1985), vectors of fungal pathogens in trees (Hinds 1972), and pollinators (Jenkins et al. 2015), non-specialists frequently encounter them and need to make confident determinations. In addition, some monotomids, such as Rhizophagus parallelocollis, Monotoma longicollis, M. spinicollis, M. johnsoni, M. picipes, and others (Kuschel 1979; Bousquet 1990; Bousquet and Laplante 1999; Jelinek 2007), are being spread worldwide through human commerce or expanding their native range (Peck and Thomas 1998), and their effects on ecosystems will remain undocumented until they are identified. However, monotomid identifications have been complicated by the inaccessibility of taxonomic literature, lack of a recent, synthetic, genus-level treatment, and inadequacy of available graphics (habitus photographs, electron micrographs, and illustrations) to interpret many diagnostic features.

To address these issues, an interactive matrix-based identification key was developed for the twelve described genera of New World Monotomidae. This key is based on a matrix of 46 characters derived from morphometrics, discrete anatomical features, distributional data, and ecology. Included are illustrations of diagnostic features and dorsal and ventral photomicrographs of reliably determined representatives of each genus. Complete taxonomic coverage was possible for some genera, allowing inclusion of photomicrographs and morphometric data for all known species.

\section{Project description}

\section{Taxonomic coverage}

This key covers 12 of the 12 genera belonging to the family Monotomidae that are currently known to occur in the New World (Bousquet 2009). 
List of the terminal taxa included in the current version of the identification key (last update November 2016)

Aneurops Sharp, 1900; Bactridium LeConte, 1861; Crowsonius Pakaluk \& Ślipiński, 1993; Europs Wollaston, 1854; Hesperobaenus LeConte, 1861; Leptipsius Casey, 1916; Macreurops Casey, 1916; Monotoma Herbst, 1793; Phyconomus LeConte, 1861; Pycnotomina Casey, 1916; Rhizophagus Herbst, 1793; Thione Sharp, 1899.

\section{Photomicrographs of terminal taxa}

Each genus included in the key has at least one associated dorsal and ventral photomicrograph. For most genera, multiple photomicrographs were provided in order to illustrate the range of intrageneric diversity. All photomicrographs represent either type specimens, authoritatively identified museum material, or material determined by the first author (TCM). Illustrative shots of important characters are provided within the key, and larger dorsal and ventral habitus photographs are included within the Fact Sheets section of the website.

\section{Characters used in the key}

\section{General features}

Characters used for identification were derived from existing literature (Sen Gupta 1988; Bousquet 2009) but then confirmed and scored from specimens in the University of Georgia Collection of Arthropods (UGCA) and the Smithsonian Institution National Museum of Natural History (NMNH). Anatomical terminology follows that of Bousquet (2009) and Sen Gupta (1988), the most comprehensive morphological treatments of Monotomidae to date.

The data matrix forming the foundation for this key is based on 46 anatomical, distributional, and ecological characters. These features are encoded into characters with a range of two to eight possible states. Most characters refer to external anatomical features of the adult form that are easily visible without preparation or dissection. Because multi-access keys provide users with greater flexibility than dichotomous keys, hard-to-view and rarely available features also are included. For example, ecological characters are provided for unusual cases when such information is available. The key includes several hind wing characters, usually visible only after dissection and preparation, because they are very valuable for separating genera. In addition, five morphometric characters are included. The diagnostic range values for these characters were based on measurements of multiple species within each genus, including measurements from as many reliably identified specimens as was reasonable. By measuring many diverse individuals representing each genus, more accurate estimates of 
the range in sizes was possible for these morphometric characters. The morphological characters are sorted by body part (head, mouthparts, thorax, scutellum, legs, hind wing, and abdomen; available via the "Subsets" button on the Lucid Player control bar, and sorted by default) allowing the user to easily focus on particular regions or preparations of a specimen. To quickly narrow some identifications, distributional characters are included.

Most characters are accompanied by supporting images and clarifying explanations within the key, as well as in the "Glossary of Terms" section (see below) of the website.

\section{List of the characters used in the key}

GENERAL: length $(\mathrm{mm})$; ratio of body length: greatest body width; body shape (lateral view); dorsal surface of the body (setation); elytral color; biology (habitat, known host associations, etc.); geographic distribution

HEAD: ratio of head length: greatest head width (including eyes); head constriction (presence/absence); ratio of temple length: longitudinal length of eye; antennal cavity on ventral side of head (presence/absence); eyes (number of facets); antennal club (number of apparent segments); antennal club (whether distinct)

MOUTHPARTS: maxillary palps (size of second segment); labial palps (size of second segment); mandibular dentation (number of teeth); mandibular cavity (presence/absence)

THORAX: ratio of pronotal length along midline: greatest pronotal width; pronotal disc (vestiture); pronotal disc (shape); lateral margin of pronotum (smooth/ crenulate); pronotal disc (impressions); pronotal microsculpture (presence/absence); pronotal puncture density (center of disc only); anterior angles of pronotum (whether projecting); procoxal cavities externally (shape); procoxal cavities (degree of separation); procoxal trochantins (exposure); scutellar microsculpture (presence/absence); scutellar setation (presence/absence); mesocoxal cavities (degree of separation)

LEGS: number of metatarsomeres of male

WINGS: elytral setigerous punctures (arrangement); setigerous punctures on epipleural fold (number of rows); hind wing (presence/absence); number of anal veins; $\mathrm{r}-\mathrm{m}$ cross (degree of development); subcubital fleck (presence/absence)

ABDOMEN: intercoxal process of abdominal ventrite (shape); metacoxal bead or femoral line (presence/absence); metacoxal bead or femoral line (length of production); first abdominal ventrite of male (special modifications); puncture rows on abdominal ventrites two-four (presence/absence); number of rows of punctures on abdominal ventrites two-four; punctures on abdominal ventrites two-four (size/shape) 


\section{Software technical specifications}

Application: Lucid Builder 3.5 (available at www.lucidcentral.org, see website for exact technical specifications and features list)

Key version: 1.0

Requirements for use: Java-enabled browser and internet connectivity

License for use of the key: Creative Commons Attribution License (CC-BY 4.0), which permits unrestricted use, distribution, and reproduction in any medium, provided the original author and source are credited

Web location: http://www.monotomidae.com/MonotomidGen.html

\section{Data resources}

The data underpinning the Lucid Key (Lucid Key files) reported in this paper are deposited in the Dryad Data Repository at http://dx.doi.org/10.5061/dryad.q9p4j.

\section{Website features}

\section{Genus fact sheets}

http://monotomidae.com/facts.html

Each of the twelve genera represented in the key are treated and figured with dorsal and ventral habitus images. For each genus, informational sections about the following subjects are provided to assist identifications: Taxonomy, Diagnosis, Biology, Distribution, List of Species (photographed and not-photographed), and Suggested References.

\section{Resources}

http://monotomidae.com/resources.html

An anatomical atlas, glossary of terms, and guide to diagnosing the beetle family Monotomidae are included here. The anatomical atlas illustrates many of the characters used in the identification key and includes an illustration of the dorsal and ventral habitus of Monotoma producta, as well as a wing illustration of Rhizophagus sayi. The glossary of terms (http://monotomidae.com/glossary.html) provides clarifiying definitions and explanations of all terms included in the interactive key, listed alphabetically, drawn from Nichols (1989), Lawrence et al. (2011), and Nearns et al. (2016). The diagnosis page (http://monotomidae.com/whatis.html) discusses characters that could diagnose a beetle as belonging to Monotomidae. It also provides photographs of taxa that are commonly misidentified as Monotomidae. 


\section{References}

http://monotomidae.com/references.html

A list of useful monotomid references is given. Links are provided to available PDFs or websites of these references when not in violation of copyright restrictions.

\section{Conclusions and future work}

During development of this identification resource, several problems became apparent. First and foremost, nearly all monotomid genera included herein require modest or extensive taxonomic work. For the Nearctic region, the problem is not as serious because most genera, with the exception of Bactridium, have been at least partially treated within the last 25 years (e.g., Bousquet 1990, 2002a, 2002b, 2003a, 2003b, 2003c; Bousquet and Laplante 1999). Bactridium requires extensive work and is currently undergoing revision by TCM. In addition, most other genera represented in the Nearctic harbor some undescribed species (e.g., Monotoma, Aneurops, and Rhizophagus). As new types of data are examined, some currently recognized polymorphic species may be recognized as species complexes. The Neotropical fauna has been far less studied; numerous undescribed species and potentially even genera exist. Species identification in this region almost always requires comparison with type material. Even genus-level identifications of Neotropical specimens should be confirmed by a specialist, though this key will narrow down options for tentative determinations considerably.

Second, the relationships between monotomid genera are poorly understood. No phylogenetic analyses of any kind have been performed for this family. Thus, some morphological characters currently used to delimit genera require investigation to test their success in characterizing monophyletic groups. Some monotypic North America genera (e.g., Pycnotomina, Macreurops, and Phyconomus) should especially be targeted, as they may represent highly autapomorphic lineages nested within other genus-level clades.

Pending completion of a number of alpha taxonomic studies and phylogenetic analyses of the family, it will be possible to update this key to include species as the terminal units, and to more rigorously define the genera, as supported by additional characters. In the meantime, the numerous habitus images and illustrations should provide enough resources for confident genus-group determinations, and the other resources provided within MonotomidGen should facilitate approximate species identification.

This key provides a flexible, powerful, and media-rich information resource for any scientist or non-professional who needs to identify monotomid beetles. In addition, it provides a framework upon which to build future identification resources for this family. Eventually, a worldwide resource for identification of monotomid beetles should be completed to identify the species being transported around the world through human activities. This will allow for quicker identifications and therefore, quicker documentation of the spread of newly adventive species. Taxonomic resources of broader scope such as MonotomidGen can assist those tasked with discovering and identifying these anthropogenic species introductions. 


\section{Acknowledgments}

This study was supported by a UGA CURO Research Grant (OFB \& JVM), H.H. Ross Memorial Fund Grant (TCM), Ernst Mayr Travel Grant from Museum of Comparative Zoology at Harvard University (TCM), and CanaColl Foundation Endowment Fund Collections Grant (Y Bousquet \& TCM).

We thank Darren Pollock (Eastern N.M. Univ.), Zach Falin (Univ. Kansas), Bob Turnbow (Enterprise, AL), the late Chuck Bellamy (CDFA), and Andy Cline (CDFA) for providing critical specimens for this study. Yves Bousquet, Nathan Lord, and Michael Thomas reviewed this manuscript and provided valuable comments and revisions. In addition, Lynette Elliott, Insect Images (Bugwood.org), Nathan Lord, Chris Mallory, the Pest and Disease Images library (PaDIL), Udo Schmidt, and Michael C. Thomas generously allowed their photos to be used for the Monotomidae diagnosis page. We would like to thank Floyd Shockley and David Furth (NMNH) for their assistance and hospitality, Gene Wright (UGA Lamar Dodd School of Art) for technical assistance, Zach McElrath for extensive coding and CSS support, and the UGA Department of Entomology for supporting this project.

\section{References}

Bousquet Y (1990) A review of the North American species of Rhizophagus Herbst and a revision of the Nearctic members of the subgenus Anomophagus Reitter (Coleoptera: Rhizophagidae). Canadian Entomologist 122: 131-171. doi: 10.4039/Ent122131-1

Bousquet Y (2002a) Family 79 - Monotomidae Laporte, 1840. In: Arnett RHJ, Thomas MC, Skelley PE, Frank JH (Eds) American Beetles (Volume 2) - Polyphaga: Scarabaeoidea through Curculionoidea. CRC Press, Boca Raton, Florida, 319-321.

Bousquet Y (2002b) Review of the genus Hesperobaenus LeConte (Coleoptera: Monotomidae) of America, north of Mexico. Pan-Pacific Entomologist 78: 197-214.

Bousquet Y (2003a) Redescription of Aneurops convergens (Sharp), new combination (Coleoptera: Monotomidae). Coleopterists Bulletin 57: 141-145. doi: 10.1649/0010-065X(2003) 057[0141:ROACSN]2.0.CO;2

Bousquet Y (2003b) Redescription of Leptipsius striatus (LeConte) and description of a new species of Leptipsius from United States (Coleoptera: Monotomidae). Coleopterists Bulletin 57: 133-140. doi: 10.1649/0010-065X(2003)057[0133:ROLSLC]2.0.CO;2

Bousquet Y (2003c) Review of the genus Europs Wollaston (Coleoptera: Monotomidae) of America, north of Mexico. Pan-Pacific Entomologist 79: 11-22.

Bousquet Y (2009) Monotomidae Laporte, 1840. In: Beutel RG, Lawrence JF, Leschen RAB (Eds) Handbook of Zoology - Coleoptera, Beetles (Volume 2). De Gruyter, New York, 319-324.

Bousquet Y, Laplante S (1999) Taxonomic review of the Canadian species of the genus Monotoma Herbst (Coleoptera: Monotomidae). Proceedings of the Entomological Society of Ontario 130: 67-96. http://www.entsocont.ca/uploads/3/0/2/6/30266933/130_67_96.pdf

Casey TL (1916) Memoirs on the Coleoptera (Volume 7). In: Lancaster PA (Ed.) The New Era Printing Company, 300 pp. doi: 10.5962/bhl.title.1159 
Cerretti P, Tschorsnig HP, Lopresti M, Giovanni FD (2012) MOSCHweb - a matrix-based interactive key to the genera of the Palaearctic Tachinidae (Insecta, Diptera). ZooKeys 205: 5-18. doi: 10.3897/zookeys.205.3409

Favret C, Miller GL (2012) AphID - Identification Technology Program, CPHST, PPQ, APHIS, USDA, Fort Collins, CO. http://AphID.AphidNet.org/ [26 April 2016]

Gregoire JC, Merlin J, Pasteels JM, Jaffuel R, Vouland G, Schvester D (1985) Biocontrol of Dendroctonus micans by Rhizophagus grandis (Coleoptera: Rhizophagidae) in the Massif Central France: a first appraisal of the mass-rearing and release methods. Zeitschrift für Angewandte Entomologie 99: 182-190. doi: 10.1111/j.1439-0418.1985.tb01977.x

Herbst JFW (1793) Natursystem aller bekannten in- und ausländischen Insekten, als eine Fortsetzung der von Büffonschen Naturgeschichte. Der Käfer Fünfter Theil. Mit 16 illuminirten Kupfertafeln. Paulischen Buchhandlung, Berlin, 392 pp. http://monotomidae.com/PDF/ herbst_1793_monotomidae.pdf

Hinds TE (1972) Insect transmission of Ceratocystis species associated with aspen cankers. Phytopathology 62(2): 221-225. doi: 10.1094/Phyto-62-221

Jelinek J (2007) Family Monotomidae Laporte, 1840. In: Löbl I, Smetana A (Eds) Catalogue of Palaearctic Coleoptera. Apollo Books, 491-495.

Jenkins DA, Millan-Hernandez C, Cline AR, McElrath TC, Irish B, Goenaga R (2015) Attraction of pollinators to atemoya (Annona squamosa x Annona cherimola) in Puerto Rico using commercial lures and food attractants. Journal of Economic Entomology 108: 1923-1929. doi: $10.1093 /$ jee/tov136

Kuschel G (1979) The genera Monotoma Herbst (Rhizophagidae) and Anommatus Wesmael (Cerylidae) in New Zealand (Coleoptera). New Zealand Entomologist 7: 44-48. doi: 10.1080/00779962.1979.9722328

LeConte JL (1861) Classification of the Coleoptera of North America. Collins, Philadelphia, 208 pp. doi: 10.5962/bhl.title.38459

Lawrence JF, Hastings AM, Seago AE, Ślipiński SA (2010) Beetles of the World. CSIRO Publishing, Clayton. http://keys.lucidcentral.org/keys/v3/botw/ [26 April 2016]

Lawrence JF, Ślipiński SA, Seago AE, Thayer MK, Newton AF and Marvaldi AE (2011) Phylogeny of the Coleoptera based on morphological characters of adults and larvae. Annales Zoologici 61: 1-217. doi: 10.3161/000345411X576725

Lord NP, Nearns EH, Miller KB (2011) Ironclad ID: Tool for diagnosing ironclad and cylindrical bark beetles (Coleoptera: Zopheridae) of North America north of Mexico. The University of New Mexico and Center for Plant Health Science and Technology, USDA, APHIS, PPQ. http://coleopterasystematics.com/ironcladid/IroncladID-Key.html

Lyons KM, Dikow T (2010) Taxonomic revision of Ectyphus Gerstaecker, 1868 and Parectyphus Hesse, 1972 with a key to world Ectyphinae (Insecta, Diptera, Mydidae). Zookeys 73: 25-59. doi: 10.3897/zookeys.73.840

Mound LA, Tree DJ, Paris D (2012) OzThrips. Centre for Biological Information Technology (CBIT), The University of Queensland, St. Lucia, Queensland. http://www.ozthrips.org/ Nearns EH, Lord NP, Lingafelter SW, Santos-Silva A, Miller KB, Zaspel JM (2016) Longicorn ID: Tool for diagnosing Cerambycoid families, subfamilies, and tribes. The University 
of New Mexico, Purdue University, and USDA APHIS PPQ Identification Technology Program (ITP). http://cerambycids.com/longicornid/ [26 April 2016]

Nichols SW (1989) The Torre-Bueno glossary of entomology. Revised edition of a glossary of entomology by J.R. de la Torre-Bueno including Supplement A by George S. Tulloch. New York Entomological Society, New York, 840 pp.

Pakaluk J, Ślipiński SA (1993) A new genus and two new species of neotropical Rhizophagidae (Coleoptera) from Trigona (Hymenoptera: Apidae) nests, with a review of rhizophagid biology. Coleopterists Bulletin 47: 349-358. http://www.jstor.org/stable/4009087

Pal TK (1996) Indoleptipsius ushae, a new genus and species of Rhizophagidae (Coleoptera: Cucujoidea). Hexapoda: Insecta Indica 8: 1-7.

Peck SB, Thomas MC (1998) A distributional checklist of the beetles (Coleoptera) of Florida. Arthropods of Florida and Neighboring Land Areas 16: 1-191. http://freshfromflorida. s3.amazonaws.com/arthropods-of-florida-vol-16.pdf

Penev L, Cerretti P, Tschorsnig HP, Lopresti M, Di Giovanni F, Georgiev T, Stoev P, Erwin T (2012) Publishing online identification keys in the form of scholarly papers. Zookeys 205: 1-3. doi: 10.3897/zookeys.205.3581

Penev L, Sharkey M, Erwin T, van Noort S, Buffington M, Seltmann K, Johnson N, Taylor M, Thompson F, Dallwitz M (2009) Data publication and dissemination of interactive keys under the open access model. Zookeys 21: 1-17. doi: 10.3897/zookeys.21.274

Sen Gupta T (1988) Review of the genera of the family Rhizophagidae (Clavicornia: Coleoptera) of the world. Memoirs of the Zoological Survey of India 17: 1-58, 24 pls. doi: 10.1002/mmnz.19950710114

Sen Gupta T, Pal TK (1995) Further observations on the family Rhizophagidae with descriptions of seven new genera. (Coleoptera, Rhizophagidae). Mitteilungen aus dem Museum für Naturkunde in Berlin Zoologisches Museum und Institut für Spezielle Zoologie (Berlin) 71: 129-146.

Sharp D (1899) Cucujidae. In: Lewis G, Matthews A (Eds) Biologia Centrali-Americana: Zoology, Botany and Archaeology - Insecta - Coleoptera (Vol. 2. Part 1). RH Porter, London, 499-563. doi: 10.5962/bhl.title.730

Sharp D (1900) Monotomidae In: Lewis G, Matthews A (Eds) Biologia Centrali-Americana: Zoology, Botany and Archaeology - Insecta - Coleoptera (Vol. 2. Part 1). RH Porter, London, 563-579. doi: 10.5962/bhl.title.730

Wollaston TV (1854) Insecta Maderensia; being an account of the insects of the islands of the Madeiran group. J. Van Voorst, London, 634 pp. doi: 10.5962/bhl.title.9060 